\title{
A neurodevelopment and neuroplasticity-based framework for early intervention in psychotic disorders
}

\author{
E. Bora ${ }^{1,2 *}$ \\ ${ }^{1}$ Department of Psychiatry, Faculty of Medicine, Dokuz Eylül University, Izmir, Turkey \\ ${ }^{2}$ Department of Psychiatry, Melbourne Neuropsychiatry Centre, University of Melbourne and Melbourne Health, Carlton South, Victoria, Australia
}

\begin{abstract}
In recent years there has been growing interest in early intervention in psychotic disorders and a number of clinical and research programmes have been developed. The clinical staging model has been an essential part of early intervention as it provides the rationale of existing programmes. In medicine, clinical staging is a valuable approach in disorders where primary pathology is progressive in nature. However, the clinical staging model of psychosis has been proposed without establishing first that schizophrenia is a primarily progressive disorder. In reviewing existing evidence, this current paper argues that cross-sectional data interpreted as supportive of clinical staging data does not consider the effects of sampling bias, problems in reliability in assessing 'soft symptoms', or false positives. Longitudinal neurobiological studies do not provide a convincing case for primarily progressive pathology in schizophrenia. Clinical progression in schizophrenia can be better conceptualised as neuroplastic changes in response to interaction between core developmental pathology and environmental stimuli. An alternative rationale for early and continuous intervention targeting neurodevelopmental abnormality and neuroplastic changes, as well as medical and psychological comorbidities, is proposed in this paper.
\end{abstract}

Received 9 May 2017; Revised 24 June 2017; Accepted 27 June 2017; First published online 11 August 2017

Key words: Early intervention, neurodevelopment, neuroplasticity, prevention, psychosis, schizophrenia.

In medicine, including psychiatry, most diseases present with significant variation in degree of severity. The degree of severity of the disorder has obvious implications for management and prognosis of patients; patients with milder disorder can generally respond to less aggressive treatment and have a better prognosis. Clinicopathological staging is a specific degree of severity approach that can only be used in medical disorders characterised by a progressive pathological process such as in cancer. Classification of cancer, Alzheimer's disease and cardiovascular disorders are good examples of the use of clinicopathological staging in management of medical conditions. In recent years, use of staging models has also been advocated for psychiatric conditions (Cosci \& Fava, 2013; Fava \& Kellner, 1993; McGorry et al. 2006; McGorry, 2010). In psychotic disorders, clinical staging models have been put forward as an underlying rationale behind the establishment of early intervention and prevention services. Clinical staging models of psychosis assume that schizophrenia is an outcome of progressive pathological process (McGorry et al. 2006;

* Address for correspondence: E. Bora, Dokuz Eylul Universitesi Tip Fakultesi, Psikiyatri Anabilimdali, Mithatpaşa cad. no 1606 inciraltı yerleşkesi 35340, Balçova/İzmir, Turkey.

(Email: emre.bora@deu.edu.tr, ibora@unimelb.edu.au)
McGorry, 2010). According to this model, remission and amelioration of symptoms is possible at every stage, though it is less likely with advancing stage (McGorry \& Van Os, 2013; McGorry et al. 2014; Nieman \& McGorry, 2015). As the underlying pathology of the disorder progresses, individuals develop more and more severe and debilitating symptoms. The most commonly used arguments by researchers to support a staging model in psychotic disorders include research findings suggesting better prognosis and effectiveness of treatment in first-episode and high-risk samples; less severe cognitive impairment in clinical and familial high-risk studies; and less severe brain imaging findings in high-risk and firstepisode patients. Clinical staging model of psychosis is also popular amongst clinicians as it offers a potential explanation for common clinical observations: for example, functional decline and decreasing efficiency of antipsychotics after repeating episodes in schizophrenia.

However, variation in severity of the disorder and clinical progression do not always reflect clinicopathological progression. Firstly, clinical progression might be related to an interaction of an underlying neurodevelopmental abnormality with environmental factors. Thus, the clinicopathological staging model is not applicable to most developmental conditions in which the medical disorder is the outcome of faulty 
development, such as a number of hereditary conditions, specifically in this case, those which include neurodevelopmental impact. While these disorders present with variable degrees of severity (such as in mental retardation or osteogenesis imperfecta), the pathological process is not generally progressive and the degree of severity of the condition is determined by variation in genetic cause. For example, in osteogenesis imperfecta, which is a congenital bone disorder characterised by brittle bones that are prone to fracture, different genetic mutations lead to different types of the disease, with significant variation in severity of clinical presentation (i.e. types I-VII) (Forlino et al. 2011). If we had not known its aetiology, it could have been possible to propose a 'clinical staging' model of osteogenesis imperfecta based on the extent of fractures and functional losses. However, clinical progression in osteogenesis imperfecta (more fractures and functional loss by time) is better explained by developmental pathology and its interaction with environmental stress (i.e. physical stress and minor trauma) than true pathological progression. Similarly, the relatively small amount of age-related amyloid accumulation or vascular changes can lead to significant cognitive symptoms in individuals with low cognitive reserve, unlike those seen in healthy subjects (Stern, 2002; La Rue, 2010). Furthermore, hereditary abnormalities are not static: in neurodevelopmental conditions, such as Fragile $X$, some clinical progression (i.e. more academic problems in late adolescence) might be a reflection of slower gain (i.e. frontal lobe functions) compared with healthy subjects (Bray et al. 2011). In the context of psychotic disorder, it could be hypothesised that variation of severity of disorder might be related to genetic factors, level of neurodevelopmental abnormalities and their relationship with environmental factors (Weinberger, 1986; Murray \& Lewis, 1987; Kapur, 2003; Bora, 2015).

Secondly, the plastic nature of the brain, which is critical for development, learning, adapting to environments and recovery from brain damage, provides another avenue for clinical progression in disorders not caused by a core progressive pathology. Neuroplastic changes in a healthy brain in response to persistent changes in effect, behaviours, thoughts, body and environment might be maladaptive in nature (Cohen et al. 1997; Cramer et al. 2011). Also, the interaction of a 'dysfunctional brain network' caused by developmental or acquired abnormalities with environmental stimuli over the years can lead to cortical reorganisation in other brain regions. Such neuroplastic changes can lead to the emergence of symptoms, followed by chronification and treatment unresponsiveness over time. For example, maladaptive neuroplastic changes could be considered to play a primary role in chronic pain in someone who has a back injury (Luo et al. 2014). In the context of psychotic disorders, emergence and gradual chronification of hallucinations and delusions, as well as associated functional decline, can be considered as a result of secondary cortical and subcortical reorganisation over the years in someone who had already baseline neurodevelopmental dysfunction in relevant brain networks. Unlike neuropathological progression, which leads to unidirectional movement across stages, these maladaptive neuroplastic changes might have bidirectional effects on illness severity overtime allowing complete or partial remission.

Finally, the effects of medical (i.e. hypertension, obesity, diabetes mellitus, treatment side effects, alcohol abuse) and psychological comorbidities (stress, trauma) can also contribute to the clinical progression of non-specific symptoms, functional decline and age-related cognitive decline, and increased incidence of dementia in old age. In the context of schizophrenia and psychotic disorders, such factors are important because they are observed more often in schizophrenia than healthy individuals. Patients with schizophrenia might also be more sensitive to the negative effects of these variables due to abnormal plasticity and developmental abnormality (Bora, 2015).

The clinical staging model of psychosis has been proposed without establishing first that schizophrenia is a primarily progressive disorder. Therefore, it is important to establish whether rationale of early intervention in schizophrenia can be best provided by staging model or alternatives discussed above.

\section{Illusion of progression in schizophrenia}

Staging models of psychosis suggest that cognitive and brain imaging abnormalities in schizophrenia gradually deteriorate as individual progress from stage I to IV (Fava \& Kellner, 1993; McGorry et al. 2006; McGorry, 2010). However, one important consideration in the comparison of patients in different 'stages' is the sample bias. First-episode psychosis (FEP) and ultra-high-risk-to-psychosis (UHR) groups typically include a higher percentage of patients with good prognosis, in comparison with chronic samples. Another important consideration is the heterogeneity of individuals in 'early stages'. Diagnosis is less clear and eventual diagnostic outcome is more variable in FEP and UHR and many patients end up with diagnoses other than schizophrenia.

The predominant consideration in interpreting available evidence is the high prevalence of false-positives in subjects who are considered to be in the early stage of psychotic disorders. In the earlier 'stages' of the illness, individuals present with mild or nonspecific symptoms (stage Ia), then progress to 
moderate but subthreshold symptoms (stage $\mathrm{Ib}$ ), and finally present with FEP (stage II). However, it seems that only a minority of individuals progress from stages Ia to II. Most individuals who meet the criteria of UHR never develop full-blown psychotic disorders (Fusar-Poli et al. 2012; 2013a; Yung et al. 2007). Transition rate is much lower in adolescents and young adults who present with mild psychotic symptoms in the community (stage Ia) (Van Os et al. 2009; Dominguez et al. 2011).

The fact that the majority of individuals in stage I, especially in stage Ia, never develop psychotic disorders, it can be concluded that a very high percentage of these cases were in fact never within the psychotic spectrum. However, staging and continuum models of psychosis tend to equate the high-prevalence psychotic-like experiences to early and subclinical forms of true psychotic symptoms. Some authors, extended this continuum to include even non-specific symptoms, such as anxiety, and advocated for early pluripotential risk syndrome rather than multiple risk syndromes for different mental disorders (McGorry, 2010). In these approaches, most non-transition is explained as either a spontaneous remission (nonpersisting) or as having a persistent but a subclinical and mild form of illness (Van Os et al. 2009; Dominguez et al. 2011). However, it is important to note that, in the absence of a biological marker, 'soft' symptoms are much less reliable than 'hard' symptoms: it can be very hard to distinguish mild psychotic experiences from other symptoms, such as dissociation. As a result, the false-positive rate would be higher as less severe psychotic experiences are assessed.

These findings have important implications for arguments put forward to support the staging model of psychosis. Most importantly, comparing different 'stages' creates the illusion of progression, as individuals with a milder psychotic condition or without true psychotic condition would have less severe or no brain imaging abnormalities and cognitive deficits and can respond to interventions, which do not work in established illness. It is also important to note that the problems surrounding the concepts of UHR and 'transition' (Van Os \& Guloksuz, 2017) can also lead to false impression of progression of neurobiological findings. For example, the differences between Ia compared with $\mathrm{Ib}$ might be mainly related to sample enrichment rather than pathological progression of psychotic illness (Fusar-Poli et al. 2016; Van Os \& Guloksuz, 2017) as help-seeking populations would include higher percentage of individuals with true psychotic conditions compared with non-help-seeking individuals with psychotic-like experiences. Similarly, the overreliance on positive symptoms for defining both risk and transition and not taking account of natural fluctuations of transdiagnostic psychotic-like symptoms (Van Os \& Guloksuz, 2017) can lead to false-positives in detecting illness onset (FEP) within the UHR samples. Again, this misclassification will lead to artificial neurobiological differences in findings of FEP (stage II) and UHR with transition (stage Ib), as latter would include individuals who have no true psychotic disorder.

\section{Evidence for illness-related pathological progression in schizophrenia}

However, these findings do not exclude the possibility of additional genuine neurodegeneration, which can be supported only by longitudinal studies.

It has been hypothesised that schizophrenia and severe mood disorders might be associated with neurodegeneration as a result of cumulative toxic effects of psychotic episodes or excessive regressive neurodevelopment (i.e. excessive pruning) (Feinberg, 1982; Keshavan et al. 1994; Anderson et al. 2014). It was also argued that the neurodegenerative process in schizophrenia had been supported by 'progressive' cognitive difficulties and cortical MRI abnormalities.

However, longitudinal neuropsychological studies in first-episode and established schizophrenia and UHR have not found evidence of cumulative cognitive decline (Szöke et al. 2008; Bonner-Jackson et al. 2010; Irani et al. 2011; Bora \& Murray, 2014). In these patient samples, cognitive deficits are stable or even slightly improved at follow-up. Also, duration of untreated psychosis has no significant effect on the severity of cognitive impairment in schizophrenia (Bora et al. $2017 a$ ). The evidence regarding the stability of cognitive functions before and after the onset of psychosis contradicts the idea that schizophrenia is a progressive dementia and does not support the staging model.

Other authors suggested that schizophrenia can be in fact characterised by premorbid cognitive decline, which starts many years before the prodrome (Reichenberg et al. 2010; Kahn \& Keefe, 2013; MacCabe et al. 2013). However, 'relative 'decline' found in these studies was a reflection of slower gain (developmental lag or arrest) in schizophrenia patients in comparison with their healthy peers. There was no consistent evidence for real decline in raw scores, as previous longitudinal studies at follow-up were agecorrected or included more challenging items (Bora, 2015). These findings do not support the idea of premorbid cognitive decline in schizophrenia either (Bora, 2014). Current evidence suggests that illnessrelated cognitive abnormalities in schizophrenia are mostly neurodevelopmental in origin. Medical and psychological comorbidities can also play an 
additional role in cognitive deficits, especially in older patients with schizophrenia (Goodman et al. 2007; Dickinson et al. 2008; Manning et al. 2009; Friedman et al. 2010; Bora, 2015; Bora et al. 2017b).

Unlike neuropsychological studies, many but not all (Sponheim et al. 1991; Roiz-Santiáñez et al. 2015; Haukvik et al. 2016) longitudinal brain imaging studies have found evidence of apparently progressive abnormalities (i.e. increasing ventricular volume and loss of gray matter) in chronic and FE schizophrenia and in UHR patients who develop psychosis at follow-up (Lieberman et al. 2001; Pantelis et al. 2003; Olabi et al. 2011; Vita et al. 2012; Fusar-Poli et al. 2013b). However, a more important question is whether these changes are related to the progressive pathology of schizophrenia or reflections of other factors. Neuroplastic, developmental and medical (including iatrogenic) factors can play a role in these MRI findings (Zipursky et al. 2013; Bora, 2015). One important confounder is antipsychotic use, as animal studies provided strong evidence suggesting that antipsychotics can decrease cortical volume (Konopaske et al. 2008). In schizophrenia, findings have suggested that cumulative exposure to antipsychotics is associated with more severe cortical gray matter losses (Ho et al. 2011; Fusar-Poli et al. 2013b).

Co-morbid medical problems, stress and alcohol and drug use are associated with brain abnormalities and can contribute to MRI findings in schizophrenia (Karl et al. 2006; Segura et al. 2009; Zatorre et al. 2012; Elofson et al. 2013; Bora, 2015). Some findings during adolescence and early adulthood might be related to differences in timing of developmental gray matter loss in schizophrenia. More importantly, not only functional imaging, but also structural imaging findings have dynamic characteristics and can be reversible (de Lange et al. 2008; Sagi et al. 2012; Taubert et al. 2012). Emergence and fluctuations of symptoms, stress, adaptive and maladaptive neuroplastic changes in response to primary pathophysiological processes or even effects of consequences of illness such as social isolation can lead to structural changes.

\section{Rationale of early intervention in schizophrenia}

Clinicopathological staging, which is a unidirectional approach, is not a suitable concept for psychotic disorders. Dynamic and bidirectional changes in illness severity overtime in schizophrenia can be better explained by maladaptive neuroplasticity in a condition characterised by a core neurodevelopmental pathology, which might be complicated by comorbidities. However, early intervention in psychotic disorders remains to be an important goal. The importance of targeting core neurodevelopmental pathology and secondary cortical and subcortical changes [in response to interaction of primary pathological abnormalities with environment (i.e. dopamine and aberrant salience)] and associated comorbidities is a sufficient ground for advocating early intervention. However, timing, duration and goal of such interventions are different than proposed in clinical staging models (Table 1).

\section{Early and continuing intervention, neuroplasticity and modification of prognosis in youth}

Effective treatment starting from FEP can increase the chance to reduce and delay neuroplastic changes leading to chronic symptoms. Treating individuals with clinical high risk is not prevention, but it has the potential to be an even more effective way of improving outcome than intervention in first-episode and has the additional benefit of decreasing the chance of catastrophic experience for the individual and family during the first-episode. However, in the absence of biological tests, the high false-positive rate remains a major challenge. On the other hand, it might be relatively late for more meaningful modification of outcome even for individuals with prodromal psychosis. If we were able to detect individuals who are in the schizophrenia spectrum with precision, it would be important to design studies investigating the potential effectiveness of pharmacological (i.e. low dose of antipsychotics or novel agents) agents given years before the onset of psychosis on prognosis and functioning. Clearly, without such groundbreaking development in our early diagnosis methods, harmful effects of such treatments would far exceed benefits in most individuals. Until such progress is achieved, psychological, social interventions and educational support would remain the main approach in management of individuals at risk for developing psychotic disorders (Table 1).

Neurocognitive rehabilitation and early social interventions, including support in education and employment, can improve functioning levels in at-risk subjects with significant cognitive impairment and developmental abnormalities. Neurostimulation and functional imaging guided feedback can also potentially be used to promote adaptive plasticity in developing brain. Ideally, these interventions would be most effective if started during childhood when brain has maximum capacity for adaptive plasticity.

Another potential strategy is development of treatments that can reverse or modify maladaptive neuroplastic changes in schizophrenia. Cognitive behaviour therapy and other psychological treatments have the potential to modify such changes or cause adaptive neuroplastic alterations that may help to reduce 
Table 1. Early interventions targeting neurodevelopmental abnormalities, neuroplastic changes and co-morbidities in psychotic disorders

\begin{tabular}{|c|c|c|c|c|}
\hline Interventions & Goals & Target age & Current & Potential \\
\hline Developmental & $\begin{array}{l}\text { Prevention and } \\
\text { modification of } \\
\text { outcome }\end{array}$ & & & \\
\hline Genetic & & $\begin{array}{l}\text { Intrauterine-early } \\
\text { childhood }\end{array}$ & Counselling & $\begin{array}{l}\text { Genetic interventions } \\
\text { Modification of gene } \\
\text { expression }\end{array}$ \\
\hline Environmental & & $\begin{array}{l}\text { Intrauterine to } \\
\text { adolescence }\end{array}$ & $\begin{array}{l}\text { Health and substance/alcohol } \\
\text { counselling in pregnancy } \\
\text { Social and medical } \\
\text { interventions-targeting effects } \\
\text { of poverty, infections, } \\
\text { malnutrition, vitamin } \\
\text { deficiency, acquired brain } \\
\text { injury during pregnancy and } \\
\text { early childhood } \\
\text { Public education }\end{array}$ & $\begin{array}{l}\text { Comprehensive and inclusive } \\
\text { public health programmes }\end{array}$ \\
\hline $\begin{array}{l}\text { Neuroplastic } \\
\text { changes }\end{array}$ & $\begin{array}{l}\text { Modification of } \\
\text { outcome }\end{array}$ & & & \\
\hline $\begin{array}{l}\text { Promoting } \\
\text { adaptive } \\
\text { neuroplasticity }\end{array}$ & $\begin{array}{l}\text { Rehabilitation of } \\
\text { developmental } \\
\text { and acquired } \\
\text { difficulties }\end{array}$ & $\begin{array}{l}\text { Childhood to } \\
\text { adolescence }\end{array}$ & $\begin{array}{l}\text { Special education } \\
\text { Neuropsychological and } \\
\text { Social cognitive training } \\
\text { School counselling }\end{array}$ & $\begin{array}{l}\text { Neurostimulation and other } \\
\text { novel therapies } \\
\text { Functional imaging guided } \\
\text { feedback }\end{array}$ \\
\hline $\begin{array}{l}\text { Preventing } \\
\text { maladaptive } \\
\text { neuroplasticity }\end{array}$ & Early treatment & $\begin{array}{l}\text { Childhood to } \\
\text { young adulthood }\end{array}$ & $\begin{array}{l}\text { CBT and other psychological } \\
\text { treatments starting from } \\
\text { clinical and genetic high-risk } \\
\text { individuals } \\
\text { Antipsychotic treatment after } \\
\text { first-episode or in selected } \\
\text { prodromal patients }\end{array}$ & $\begin{array}{l}\text { Diagnosis in prespychotic } \\
\text { period with high accuracy } \\
\text { Novel pharmacological } \\
\text { agents or low dose } \\
\text { antipsychotics in } \\
\text { prepsychotic period }\end{array}$ \\
\hline $\begin{array}{l}\text { Reversing } \\
\text { maladaptive } \\
\text { neuroplasticity }\end{array}$ & $\begin{array}{r}\text { Preventing } \\
\text { chronicity }\end{array}$ & $\begin{array}{l}\text { Childhood to } \\
\text { adulthood }\end{array}$ & $\begin{array}{l}\mathrm{CBT} \text { and other psychological } \\
\text { treatments }\end{array}$ & $\begin{array}{l}\text { Medications (i.e. targeting } \\
\text { glutamatergic system) } \\
\text { Neuroplasticity-based } \\
\text { psychological treatments } \\
\text { Advanced neurostimulation } \\
\text { methods }\end{array}$ \\
\hline Co-morbidities & $\begin{array}{l}\text { Prevention of } \\
\text { further functional } \\
\text { decline }\end{array}$ & & & \\
\hline Medical & & $\begin{array}{l}\text { Adolescence to } \\
\text { adulthood }\end{array}$ & $\begin{array}{l}\text { Lifestyle interventions } \\
\text { Early and effective monitoring } \\
\text { and management of medical } \\
\text { conditions } \\
\text { Rationale choice of } \\
\text { psychotropics }\end{array}$ & $\begin{array}{l}\text { Novel antipsychotics with } \\
\text { minimal metabolic side } \\
\text { effects } \\
\text { Genetic risk profiling for } \\
\text { medical disorders and } \\
\text { including this information in } \\
\text { psychiatric treatment } \\
\text { decisions }\end{array}$ \\
\hline Psychological & & $\begin{array}{l}\text { Childhood to } \\
\text { adulthood }\end{array}$ & $\begin{array}{l}\text { Counselling and } \\
\text { psychoeducation } \\
\text { Trauma focused therapies } \\
\text { CBT and other psychological } \\
\text { therapies for depression and } \\
\text { anxiety } \\
\text { Antidepressants }\end{array}$ & $\begin{array}{l}\text { Modifications to adjust } \\
\text { existing therapies to needs of } \\
\text { youth, people with psychosis } \\
\text { and developmental } \\
\text { abnormalities }\end{array}$ \\
\hline
\end{tabular}


Table 1 (cont.)

\begin{tabular}{|c|c|c|c|c|}
\hline Interventions & Goals & Target age & Current & Potential \\
\hline Social & & $\begin{array}{l}\text { Childhood to } \\
\text { adulthood }\end{array}$ & $\begin{array}{l}\text { Interventions for employment } \\
\text { and social support } \\
\text { Family and marital therapies } \\
\text { Public education, advocacy and } \\
\text { reducing stigma }\end{array}$ & $\begin{array}{l}\text { More comprehensive and } \\
\text { inclusive social programmes }\end{array}$ \\
\hline $\begin{array}{l}\text { Substance/ } \\
\text { alcohol }\end{array}$ & & $\begin{array}{l}\text { Adolescence to } \\
\text { adulthood }\end{array}$ & $\begin{array}{l}\text { Youth friendly drug/alcohol } \\
\text { rehabilitation programmes }\end{array}$ & $\begin{array}{l}\text { Modifications to adjust } \\
\text { existing programmes to needs } \\
\text { of people with psychosis and } \\
\text { developmental abnormalities }\end{array}$ \\
\hline
\end{tabular}

symptoms. It may be possible to develop pharmacological (i.e. targeting glutamate receptors) or other strategies to reverse such neuroplastic changes.

It is also essential to emphasise the importance of continuing these interventions during the life course of individuals with psychotic disorders. Gains after time-limited intense early intervention can be lost at follow-up without adequate support in adulthood. Chronification can happen in coming years, even after effective early intervention, and many people can have their first-episode well into their thirties or later. Sufficient allocation of financial and other resources during the lifetime of the individual is important.

\section{Prevention of effects of medical, social and psychological comorbidities leading to functional decline in schizophrenia}

While the core pathology of schizophrenia is neurodevelopmental in origin, common medical comorbidities (i.e. cardiovascular) affecting humankind might have greater impact on individuals with schizophrenia. Introducing evidence-based interventions for cardiovascular health, including diet and exercise in early years of illness, can have significant long-term benefits. Modifying these treatments to the needs of individuals with schizophrenia and youth is essential. Education and support to engage with such programmes should start from at-risk state and first-episode. Employment support and other social interventions and psychological counselling for at-risk and first-episode individuals for alcohol/drug abuse, past trauma and stress associated with consequences of illness can be beneficial to prevent further functional decline (Table 1).

\section{Early intervention, neurodevelopment and prevention in childhood and intrauterine life}

True prevention of schizophrenia can only be achieved by interventions targeting neurodevelopment in intrauterine life and early years of post-natal life. The effects of vulnerability of 'schizophrenia genes' are likely to be non-specific and is associated with more general neurodevelopmental problems that increase the risk of multiple disorders, including schizophrenia. Interventions targeting expressions of such deficits in limited brain regions that are associated with psychosis can also be possible. With advancement of our knowledge in the genetics of schizophrenia(s), risk analysis based on genotyping of individuals (i.e. polygenic risk scores) might be routinely available in the future (Kendler, 2016). Specific and non-specific genetic interventions remain to be futuristic and have many ethical issues. However, public health and medical health interventions targeting environmental factors that have negative impact on brain development in pregnancy and early years (i.e. nutrition, vitamin $\mathrm{D}$, birth complications, drug and alcohol use in pregnancy, trauma and poverty) can make a significant impact (McGrath et al. 2004; Boeke et al. 2013) (Table 1).

\section{Conclusion}

Clinicopathological staging is not applicable in schizophrenia management. True prevention of schizophrenia can only be achieved by interventions targeting neurodevelopment in early life. However, early (and continuous) interventions targeting neuroplastic changes in adolescence and adults with schizophrenia, and nonspecific interventions starting from early days of psychotic disorder, can improve outcome. Developing methods with high accuracy to detect at-risk individuals who are truly in the schizophrenia-spectrum during childhood and adolescence can substantially improve the efficiency of early intervention.

\section{Acknowledgement}

Dr Bora is supported by The Scientific and Technological Research Council of Turkey (TÜBİTAK) BIDEB2232 fellowship. 


\section{Declaration of Interest}

None.

\section{References}

Anderson KK, Voineskos A, Mulsant BH, George TP, Mckenzie KJ (2014). The role of untreated psychosis in neurodegeneration: a review of hypothesized mechanisms of neurotoxicity in first-episode psychosis. Canadian Journal of Psychiatry 59, 513-517.

Boeke CE, Gillman MW, Hughes MD, Rifas-Shiman SL, Villamor E, Oken E (2013). Choline intake during pregnancy and child cognition at age 7 years. American Journal of Epidemiology 177, 1338-1347.

Bonner-Jackson A, Grossman LS, Harrow M, Rosen C (2010). Neurocognition in schizophrenia: a 20-year multifollow-up of the course of processing speed and stored knowledge. Comprehensive Psychiatry 51, 471-479.

Bora E (2014). Developmental lag and course of cognitive deficits from the premorbid to postonset period in schizophrenia. American Journal of Psychiatry 171, 369.

Bora E (2015). Neurodevelopmental origin of cognitive impairment in schizophrenia. Psychological Medicine 45, 1-9.

Bora E, Akdede BB, Alptekin K (2017a). The relationship between cognitive impairment in schizophrenia and metabolic syndrome: a systematic review and metaanalysis. Psychological Medicine 47, 1030-1040.

Bora E, Murray RM (2014). Meta-analysis of cognitive deficits in ultra-high risk to psychosis and first-episode psychosis: do the cognitive deficits progress over, or after, the onset of psychosis? Schizophrenia Bulletin 40, 744-755.

Bora E, Yalincetin B, Akdede BB, Alptekin K (2017b). Duration of untreated psychosis and neurocognition in first-episode psychosis: a meta-analysis. Schizophrenia Research (in press). doi: 10.1016/j.schres.2017.06.021.

Bray S, Hirt M, Jo B, Hall SS, Lightbody AA, Walter E, Chen K, Patnaik S, Reiss AL (2011). Aberrant frontal lobe maturation in adolescents with fragile $X$ syndrome is related to delayed cognitive maturation. Biological Psychiatry 70, 852-858.

Cohen LG, Celnik P, Pascual-Leone A, Corwell B, Falz L, Dambrosia J, Honda M, Sadato N, Gerloff C, Catalá MD, Hallett M (1997). Functional relevance of cross-modal plasticity in blind humans. Nature 389, 180-183.

Cosci F, Fava GA (2013). Staging of mental disorders: systematic review. Psychotherapy and Psychosomatics 82, 20-34.

Cramer SC, Sur M, Dobkin BH, O'Brien C, Sanger TD, Trojanowski JQ, Rumsey JM, Hicks R, Cameron J, Chen D, Chen WG, Cohen LG, deCharms C, Duffy CJ, Eden GF, Fetz EE, Filart R, Freund M, Grant SJ, Haber S, Kalivas PW, Kolb B, Kramer AF, Lynch M, Mayberg HS, McQuillen PS, Nitkin R, Pascual-Leone A, Reuter-Lorenz P, Schiff N, Sharma A, Shekim L, Stryker M, Sullivan EV, Vinogradov S (2011). Harnessing neuroplasticity for clinical applications. Brain 134, 1591-1609.

de Lange FP, Koers A, Kalkman JS, Bleijenberg G, Hagoort P, van der Meer JW, Toni I (2008). Increase in prefrontal cortical volume following cognitive behavioural therapy in patients with chronic fatigue syndrome. Brain 131, 2172-2180.

Dickinson D, Gold JM, Dickerson FB, Medoff D, Dixon LB (2008). Evidence of exacerbated cognitive deficits in schizophrenia patients with comorbid diabetes. Psychosomatics 49, 123-131.

Dominguez MD, Wichers M, Lieb R, Wittchen HU, van Os J (2011). Evidence that onset of clinical psychosis is an outcome of progressively more persistent subclinical psychotic experiences: an 8-year cohort study. Schizophrenia Bulletin 37, 84-93.

Elofson J, Gongvatana W, Carey KB (2013). Alcohol use and cerebral white matter compromise in adolescence. Addictive Behaviours 38, 2295-2305.

Fava GA, Kellner R (1993). Staging: a neglected dimension in psychiatric classification. Acta Psychiatrica Scandinavica 87, 225-230.

Feinberg I (1982). Schizophrenia: caused by a fault in programmed synaptic elimination during adolescence? Journal of Psychiatric Research 17, 319-334.

Forlino A, Cabral WA, Barnes AM, Marini JC (2011). New perspectives on osteogenesis imperfecta. Nature Review Endocrinology 7, 540-557.

Friedman JI, Wallenstein S, Moshier E, Parrella M, White L, Bowler S, Gottlieb S, Harvey PD, McGinn TG, Flanagan L, Davis KL (2010). The effects of hypertension and body mass index on cognition in schizophrenia. American Journal of Psychiatry 167, 1232-1239.

Fusar-Poli P, Bechdolf A, Taylor MJ, Bonoldi I, Carpenter WT, Yung AR, McGuire P (2013a). At risk for schizophrenic or affective psychoses? A meta-analysis of DSM/ICD diagnostic outcomes in individuals at high clinical risk. Schizophrenia Bulletin 39, 923-932.

Fusar-Poli P, Bonoldi I, Yung AR, Borgwardt S, Kempton MJ, Valmaggia L, Barale F, Caverzasi E, McGuire P (2012). Predicting psychosis: meta-analysis of transition outcomes in individuals at high clinical risk. Archives of General Psychiatry 69, 220-229.

Fusar-Poli P, Smieskova R, Kempton MJ, Ho BC, Andreasen NC, Borgwardt S (2013b). Progressive brain changes in schizophrenia related to antipsychotic treatment? A metaanalysis of longitudinal MRI studies. Neuroscience and Biobehavioral Review 37, 1680-1691.

Fusar-Poli P, Schultze-Lutter F, Cappucciati M, Rutigliano G, Bonoldi I, Stahl D, Borgwardt S, Riecher-Rössler A, Addington J, Perkins DO, Woods SW, McGlashan T, Lee J, Klosterkötter J, Yung AR, McGuire P (2016). The Dark Side of the Moon: Meta-analytical Impact of Recruitment Strategies on Risk Enrichment in the Clinical High Risk State for Psychosis. Schizophrenia Bulletin 42, 732-43.

Goodman C, Finkel B, Naser M, Andreyev P, Segev Y, Kurs R, Melamed Y, Bleich A (2007). Neurocognitive deterioration in elderly chronic schizophrenia patients with and without PTSD. Journal of Nervous and Mental Disease 195, 415-420.

Haukvik UK, Hartberg CB, Nerland S, Jørgensen KN, Lange EH, Simonsen C, Nesvåg R, Dale AM, Andreassen OA, Melle I, Agartz I (2016). No progressive brain changes during a 1-year follow-up of patients with first-episode psychosis. Psychological Medicine 46, 589-598. 
Ho BC, Andreasen NC, Ziebell S, Pierson R, Magnotta V (2011). Long-term antipsychotic treatment and brain volumes: a longitudinal study of first-episode schizophrenia. Archives of General Psychiatry 68, 128-137.

Irani F, Kalkstein S, Moberg EA, Moberg PJ (2011). Neuropsychological performance in older patients with schizophrenia: a meta-analysis of cross-sectional and longitudinal studies. Schizophrenia Bulletin 37, 1318-1326.

Kahn RS, Keefe RSE (2013). Schizophrenia is a cognitive disorder. time for change for focus. JAMA Psychiatry 70, 1107-1112.

Kapur S (2003). Psychosis as a state of aberrant salience: a framework linking biology, phenomenology, and pharmacology in schizophrenia. American Journal of Psychiatry 160, 13-23.

Karl A, Schaefer M, Malta LS, Dörfel D, Rohleder N, Werner A (2006). A meta-analysis of structural brain abnormalities in PTSD. Neuroscience and Biobehavioral Review 30, 1004-1031.

Kendler KS (2016). The schizophrenia polygenic risk score: to what does It predispose in adolescence? JAMA Psychiatry 73, 193-194.

Keshavan MS, Anderson S, Pettegrew JW (1994). Is schizophrenia due to excessive synaptic pruning in the prefrontal cortex? The Feinberg hypothesis revisited. Journal of Psychiatric Research 28, 239-265.

Konopaske GT, Dorph-Petersen KA, Sweet RA, Pierri JN, Zhang W, Sampson AR, Lewis DA (2008). Effect of chronic antipsychotic exposure on astrocyte and oligodendrocyte numbers in macaque monkeys. Biological Psychiatry 63, 759-765.

La Rue A (2010). Healthy brain aging: role of cognitive reserve, cognitive stimulation, and cognitive exercises. Clinical Geriatric Medicine 26, 99-111.

Lieberman J, Chakos M, Wu H, Alvir J, Hoffman E, Robinson D, Bilder R (2001). Longitudinal study of brain morphology in first episode schizophrenia. Biological Psychiatry 49, 487-499.

Luo C, Kuner T, Kuner R (2014). Synaptic plasticity in pathological pain. Trends Neuroscience 37, 343-355.

MacCabe JH, Wicks S, Löfving S, David AS, Berndtsson Å, Gustafsson JE, Allebeck P, Dalman C (2013). Decline in cognitive performance between ages 13 and 18 years and the risk for psychosis in adulthood: a Swedish longitudinal cohort study in males. JAMA Psychiatry 70, 261-270.

Manning V, Betteridge S, Wanigaratne S, Best D, Strang J, Gossop M (2009). Cognitive impairment in dual diagnosis inpatients with schizophrenia and alcohol use disorder. Schizophrenia Research 114, 98-104.

McGorry P, van Os J (2013). Redeeming diagnosis in psychiatry: timing versus specificity. Lancet 381, 343-345.

McGorry P, Keshavan M, Goldstone S, Amminger P, Allott K, Berk M, Lavoie S, Pantelis C, Yung A, Wood S, Hickie I (2014). Biomarkers and clinical staging in psychiatry. World Psychiatry 13, 211-223.

McGorry PD (2010). Staging in neuropsychiatry: a heuristic model for understanding, prevention and treatment. Neurotoxicity Research 18, 244-255.

McGorry PD, Hickie IB, Yung AR, Pantelis C, Jackson HJ (2006). Clinical staging of psychiatric disorders: a heuristic framework for choosing earlier, safer and more effective interventions. Australian and New Zealand Journal of Psychiatry 40, 616-622.

McGrath J, Saari K, Hakko H, Jokelainen J, Jones P, Järvelin MR, Chant D, Isohanni M (2004). Vitamin D

supplementation during the first year of life and risk of schizophrenia: a Finnish birth cohort study. Schizophrenia Research 67, 237-245.

Murray RM, Lewis SW (1987). Is schizophrenia a neurodevelopmental disorder? BMJ (Clinical Research Edition) 295, 681-682.

Nieman DH, McGorry PD (2015). Detection and treatment of at-risk mental state for developing a first psychosis: making up the balance. Lancet Psychiatry 2, 825-834.

Olabi B, Ellison-Wright I, McIntosh AM, Wood SJ, Bullmore E, Lawrie SM (2011). Are there progressive brain changes in schizophrenia? A meta-analysis of structural magnetic resonance imaging studies. Biological Psychiatry 70, 88-96.

Pantelis C, Velakoulis D, McGorry PD, Wood SJ, Suckling J, Phillips LJ, Yung AR, Bullmore ET, Brewer W, Soulsby B, Desmond P, McGuire PK (2003). Neuroanatomical abnormalities before and after onset of psychosis: a crosssectional and longitudinal MRI comparison. Lancet 361 (9354), 281-288.

Reichenberg A, Caspi A, Harrington H, Houts R, Keefe RS, Murray RM, Poulton R, Moffitt TE (2010). Static and dynamic cognitive deficits in childhood preceding adult schizophrenia: a 30-year study. American Journal of Psychiatry 167, 160-169.

Roiz-Santiáñez R, Ortiz-García de la Foz V, Ayesa-Arriola $R$, Tordesillas-Gutiérrez $D$, Jorge R, Varela-Gómez N, Suárez-Pinilla $\mathrm{P}$, Córdova-Palomera A, Navasa-Melado JM, Crespo-Facorro B (2015). No progression of the alterations in the cortical thickness of individuals with schizophrenia-spectrum disorder: a three-year longitudinal magnetic resonance imaging study of first-episode patients. Psychological Medicine 45, 2861-2871.

Sagi Y, Tavor I, Hofstetter S, Tzur-Moryosef S, BlumenfeldKatzir T, Assaf Y (2012). Learning in the fast lane: new insights into neuroplasticity. Neuron 73, 1195-1203.

Segura B, Jurado MA, Freixenet N, Falcón C, Junqué C, Arboix A (2009). Microstructural white matter changes in metabolic syndrome: a diffusion tensor imaging study. Neurology 73, 438-444.

Sponheim SR, Iacono WG, Beiser M (1991). Stability of ventricular size after the onset of psychosis in schizophrenia. Psychiatry Research 40, 21-29.

Stern Y (2002). What is cognitive reserve? Theory and research application of the reserve concept. Journal of International Neuropsychological Society 8, 448-460.

Szöke A, Trandafir A, Dupont ME, Méary A, Schürhoff F, Leboyer M (2008). Longitudinal studies of cognition in schizophrenia: meta-analysis. British Journal of Psychiatry 192, 248-257.

Taubert M, Villringer A, Ragert P (2012). Learning-related gray and white matter changes in humans: an update. Neuroscientist 18, 320-325.

Van Os J, Guloksuz S (2017). A critique of the 'ultra-high risk' and 'transition' paradigm. World Psychiatry 16, 200-206. 
Van Os J, Linscott RJ, Myin-Germeys I, Delespaul P, Krabbendam L (2009). A systematic review and meta-analysis of the psychosis continuum: evidence for a psychosis proneness-persistence-impairment model of psychotic disorder. Psychological Medicine 39, 179-195.

Vita A, De Peri L, Deste G, Sacchetti E (2012). Progressive loss of cortical gray matter in schizophrenia: a metaanalysis and meta-regression of longitudinal MRI studies. Translational Psychiatry 2, e190.

Weinberger DR (1986). The pathogenesis of schizophrenia: a neurodevelopmental theory. In The Neurology of
Schizophrenia (ed. R. A. Nasrallah, D. R. Weinberger), pp. 387-405. Amsterdam, Elsevier: Elsevier.

Yung AR, Yuen HP, Berger G, Francey S, Hung TC, Nelson B, Phillips L, McGorry P (2007). Declining transition rate in ultra high risk (prodromal) services: dilution or reduction of risk? Schizophrenia Bulletin 33, 673-681.

Zatorre RJ, Fields RD, Johansen-Berg H (2012). Plasticity in gray and white: neuroimaging changes in brain structure during learning. Nature Neuroscience 15, 528-536.

Zipursky RB, Reilly TJ, Murray RM (2013). The myth of schizophrenia as a progressive brain disease. Schizophrenia Bulletin 39, 1363-1372. 